\title{
Technology Diffusion and Trade Liberalization
}

\author{
${ }^{1}$ Department of Applied Economics, Utah State University, 4835 Old Main Hill, Logan, UT 84322, USA, E-mail: \\ reza.oladi@usu.edu \\ ${ }^{2}$ Department of Economics, University of Texas at San Antonio, 1 UTSA Circle, San Antonio, TX 78249, USA
}

\begin{abstract}
:
We consider a developing economy where multinational corporations compete with foreign and local firms in a monopolistically competitive market. The focus of our paper is on consequences of a policy mix of tariffs and foreign direct investment (FDI) tax in a developing economy. We assume all firms are technologically heterogeneous and that foreign firms are technologically superior to local firms. Central to our model is the assumption that FDI activities by multinational corporations would lead to diffusion of technology in the developing economy. We show the existence of a non-trivial equilibrium where most technologically advanced foreign firms emerge as multinationals, engage in FDI activities and this in turn leads to the diffusion of technology. We also show that trade liberalization without liberalization of foreign investment may lead to the protection of most technological backward local firms in the developing economy and such liberalization can reduce the welfare of a representative consumer.
\end{abstract}

Keywords: foreign direct investment, technology diffusion, liberalization

JEL classification: F12, F13, F23, O33, L13

Dol: $10.1515 /$ bejeap-2016-0075

\section{Introduction}

The rapid pace of globalization over the past few decades has been to a large extent through expansion of foreign trade and international movement of capital. On the one hand, multinational corporations have played a major role in bringing about tremendous growth in the flow of foreign direct investment (FDI). On the other hand, pursuit of trade liberalization and reduction in foreign investment barriers by governments have been crucial factors in facilitating such growth in international trade and foreign investment. While interplaying of trade and investment liberalizations and its effects on growth of international trade and investment are generally applicable to any economy (developed or developing), there are additional issues specific to developing economies. One such issue is the stark technological differences between developed and developing economies and the possible diffusion of technology from developed countries to the less technologically advanced developing countries. In this paper we study the interaction between trade and FDI liberalization in a developing country as in Chao and Yu (1997) and its effects on FDI activities by multinational corporations. We then analyze their role in technology diffusion, assuming that all firms (foreign and local) are technologically heterogeneous.

In sum, this paper shows that trade liberalization may result in non-uniform outcomes in developing countries due to the effects of technology diffusion and its pattern. Foreign firms alter their decision on export to developing countries versus their FDI in these countries in response to trade liberalization in developing countries. As FDI is a carrier of foreign technology and causes technology diffusion in the host countries, trade liberalization can influence the flow of more advanced foreign technology into these developing countries. Also, technological heterogeneity of local firms in developing countries plays a crucial role and can determine the pattern of technology diffusion. If local firm heterogeneity leads to a non-uniform pattern of technology diffusion such that more technologically advanced local firms benefit more from diffusion of technology, then trade liberalization (without a change in investment policy) may have a more negative impact (as far as the benefit of diffusion is concerned) on technologically advanced local firms compared with the less advanced local firms. Thus, trade liberalization without liberalizing foreign investment may lead to the protection of small and technologically backward local firms in developing countries. Clearly, this is in sharp contrast with a generally held view by some policy makers and voiced by popular press that trade harms small businesses (for example, see Business (2013)). Hence, this result begs for an explanation at the outset of our paper. To make our case for such a possibility, consider footwear industry in India as an example. Local firms range from small shoe makers with backward handmade technology to automated shoe-making manufacturing. Since small low tech firms may not use computers in their production technology, presence of multinational corporation through 
FDI has little positive impact on these low tech firms as far as technology diffusion is concerned. However, the more foreign direct invest in Indian footwear industry will have positive technology spillover on more technologically advanced and automated local shoe manufacturing. On the other hand, the decision of foreign firms to invest and produce shoes in India versus producing shoes in their own countries and exporting to India depends on Indian tariff rates and corporate tax rates on multinationals. Due to fixed cost of investing abroad, the most technologically advanced (which are also large) foreign firms can engage in foreign investment activities. Hence, more foreign investment in India may result in more diffusion of technology. Now suppose India experiences trade liberalization without liberalizing foreign investment. This one-dimensional type of liberalization may induce less foreign FDI and more import of shoes into India as foreign firms opt more for export to India and less FDI. In turn, this may weaken the competitiveness of high tech shoe makers relative to low tech ones through technology diffusion channel, ceteris paribus, resulting in protection of low-tech firms. The flip side of this finding is that if developing countries pursue protectionary trade policies in this kind of environment, such policies may fail to protect less technologically advanced local firms.

The literature on multinational corporations and FDI is rich and extensive. A branch of this literature, that is particularly related to our paper, studies the choice between export and foreign investment and its implications (e.g., see Batra and Ramachandran (1980) and more recently Helpman, Melitz, and Yeaple (2004) and Mukherjee (2011), among others). ${ }^{1}$ Another strand of literature, to which our paper is related and contributes to, focuses on the effects that FDI has on diffusion of technology in developing countries (see Findlay (1978)). ${ }^{2}$ In the current paper we build upon Dixit and Stiglitz (1977) and introduce a continuum of heterogeneous firms that produce a continuum of differentiated goods (see also Baldwin and Forslid (2010), Dinopoulos and Unel (2013), Helpman, Melitz, and Yeaple (2004), Melitz (2003), and Marjit and Kar (2012)). ${ }^{3}$ Baldwin and Forslid (2010) also consider trade liberalization when firms are heterogeneous. In contrast to Baldwin and Forslid (2010), we study the implications of a policy mix of tariffs and taxes on multinationals vis-a-vis the choice between FDI and export to a developing country by foreign firms. We consider a case in which foreign firms compete with local firms in the developing country in a monopolistic competitive industry. We define firm heterogeneity on the basis of technological levels of firms as in Helpman, Melitz, and Yeaple (2004). We assume that all local firms in the developing country (which are also heterogeneous in their technological advancement) are technologically backward relative to foreign firms. Also, in contrast to both Helpman, Melitz, and Yeaple (2004) and Baldwin and Forslid (2010), we assume that FDI activities by foreign firms lead to diffusion of their superior technology in developing economies. There are empirical studies that support this hypothesis. ${ }^{4}$ As it will be shown, this central feature of our model has crucial consequences on the theory of multinational corporations and its implications are essential in our understanding of the effects of trade liberalization for developing economies.

We first show that for a policy mix of import tariffs and tax on profits of multinational corporations imposed by the developing country, there exists an equilibrium whereby the more technologically advanced foreign firms will opt for FDI (i.e., become multinational) while the less technological advanced foreign firms will export their goods to the developing country (hereafter, we simply call these goods imported goods, from the point of view of the developing countries). Although this particular observation is similar to Helpman, Melitz, and Yeaple (2004) where they showed that the most productive firms in a country opt for FDI, while mid-level productive firms will export their goods and the least productive firm will serve the domestic market only, our focus is on policy mix for a developing country and the consequences of such a policy mix for a developing economy given the possibility of technology diffusion (absent in both Helpman, Melitz, and Yeaple (2004) and Baldwin and Forslid (2010)).

While a large portion of literature on theory of trade liberalization deals with unidimensional liberalization, most economies face many distortions. ${ }^{5}$ As far as trade liberalization is concerned, it is crucial to consider the confluence of liberalization of trade and foreign investment. The combined influence of the trade distortions (such as tariffs) and capital market distortions (such as tax on FDI) is particularly amplified in our set up due to the technology diffusion effects. Studies on multiple distortions are also abundant and there is an extensive body of literature that focuses on various combination of commercial policies (for example, see Ruffin (1979)) as well as combination of commercial policies and other domestic taxes (for example, see Batra and Ramachandran (1980)). ${ }^{6}$ Next, we show that trade liberalization has profound effects on FDI, the local firms, as well as the aggregate industry in developing countries. Most notably, as we stated earlier in this introduction, we show that trade liberalization by the developing country may lead to the protection of the most technologically backward local firms. The paradoxical aspect of this result is due to the generally held view that trade barriers are designed to protect local firms that would otherwise not survive, including the less technologically advanced firms. According to this widely held view, these firms are expected to be the first victim of trade liberalization. We will show that this need not be true, given that trade liberalization is coupled with liberalization of foreign investment. Finally, we study the effects of changes in a mix of trade policies on the welfare of a representative consumer. 
Our paper has very important policy implications for firms in developing countries when facing trade liberalization. Empirical studies that address the effects of trade liberalization on local firms in developing countries are extensive. While the earlier studies present a mixed picture (for example, see Krishna and Mitra (1998)), more recent ones support the positive effects of trade liberalization on firm productivity. One of the best case studies for the effects of trade liberalization is India, which undertook vast liberalization reforms in 1990s. The empirical investigation of Indian experience is also rather rich (see Krishna and Mitra (1998), among others).

Our theoretical results begs for studying empirically the effects trade liberalization without FDI liberalization may have on developing economies. Again, India experience of 1990s may offer a good case study. Our results constitute a foundation for empirical re-examination of Indian liberalization of 1990s and effects of such reforms on firms with a wide range of technological heterogeneity.

The rest of this paper is organized as follows. Section 1 sets up a theory of FDI and multinational corporation for a developing country with a focus on a policy mix at the presence of technologically heterogeneous firms. We will present an extended model that incorporates technology diffusion in the developing economy in Section 3. Section 4 studies welfare consequences and Section 5 concludes that paper. All proofs for the results of Section 2-Section 4 are presented in Appendix A. We also study robustness of our results by constructing a more complex model and revisiting our results in Appendix B.

\section{The Setup}

Consider a developing economy with a possible range of differentiated goods denoted by $\Omega \equiv[0, \bar{\omega}]$. The consumer's preferences are represented by a C.E.S. utility function:

$$
U=\left[\int_{\omega \in \Omega}[q(\omega)]^{\rho} d \omega\right]^{\frac{1}{\rho}}
$$

where $q(\omega)$ is quantity of good $\omega \in \Omega$ and $\rho \in(0,1)$. As in Dixit and Stiglitz (1977), the aggregate industry output is $Q \equiv U$ and the industry aggregate price is given by:

$$
P=\left[\int_{\omega \in \Omega}[p(\omega)]^{1-\sigma} d \omega\right]^{\frac{1}{1-\sigma}}
$$

where $p(\omega)$ is the price of good $\omega \in \Omega$ and $\sigma=1 /(1-\rho)>1$ is the demand elasticity of substitution. We assume throughout the paper that the aggregate industry demand is unitary elastic, i.e. $\epsilon \equiv(d Q / d P)(P / Q)=-1$. Following Beladi and Oladi (2016) the equilibrium consumption of good $\omega \in \Omega$ is given by:

$$
q(\omega)=Q[\xi(\omega)]^{-\sigma}
$$

where $\xi(\omega) \equiv p(\omega) / P$ is the intra-industry relative price of variety $\omega$. That is, the optimal consumption of any good is an increasing (decreasing) function of aggregate industry output (its intra-industry relative price). We coin $\xi(\omega)$ as a measure of competitive position of good (firm) $\omega \in \Omega{ }^{7}$ The lower $\xi$ is, the better is a firm's competitive position within its industry.

Similarly, the equilibrium expenditure for any good $\omega \in \Omega$ is given by:

$$
e(\omega)=E[\xi(\omega)]^{1-\sigma}
$$

where $E \equiv P Q$ is the aggregate industry expenditure (i.e., $E=\int_{\omega \in \Omega} e(\omega) d \omega$ ), implying that the equilibrium spending on any variety is increasing in aggregate industry expenditure and decreasing in its intra-industry relative price.

Assume that all goods with $\omega \leq \omega_{i}$ for $\omega_{i} \in \Omega$ are produced by domestic local firms and whereas goods with $\omega>\omega_{i}$ are produced by foreign firms where some of them are multinational corporations. Foreign goods can either be produced abroad and imported or be produced via FDI in our developing country. Labor is the only production input for all goods. The cost of production has a fixed and a variable component (both in labor). However, FDI also requires an additional fixed cost. We assume, as in Krugman (1980) albeit without firm heterogeneity, that the production technologies for all firms exhibit increasing returns to scale. Accordingly, the labor usage for good $\omega \in[0, \bar{\omega}]$ is given by: 


$$
l(\omega)= \begin{cases}\delta+\frac{q(\omega)}{\gamma(\omega)} & \omega \leq \omega_{f} \\ \delta+\delta_{f}+\frac{q(\omega)}{\gamma(\omega)} & \omega>\omega_{f}\end{cases}
$$

where $\gamma(\omega)>0$ is the measure of technology level for the firm producing good $\omega \in \Omega, \delta$ is the common fixed cost of production, and $\delta_{f}$ denotes the fixed cost of FDI. Moreover, $\omega_{i} \leq \omega_{f} \in \Omega$. Since there is a oneto-one relationship between goods and firms (see Dixit and Stiglitz 1977), we also identify firms with $\omega \in \Omega$. We assume that the technology measure is increasing in good (or firm) index, i.e., $\gamma^{\prime}>0$. Here, we also assumed for now that all foreign goods $\omega \in\left(\omega_{i}, \omega_{f}\right]$ are imported by our developing economy while all goods $\omega \in\left(\omega_{f}, \bar{\omega}\right]$ are produced by multinationals through FDI in the developing economy where $\omega_{i}$ and $\omega_{f}$ are lower and upper bounds on index of imported goods, respectively. That is, among the foreign firms, the more technological superior ones are multinationals. ${ }^{8}$ In fact, we show shortly that this sorting of foreign firms appears as an equilibrium. ${ }^{9}$ Since each firm faces a residual demand with a constant elasticity, it chooses the same profit maximizing markup $(1 / \rho)$, leading to the following pricing rule:

$$
p(\omega)= \begin{cases}\frac{W}{\rho \gamma(\omega)} & \omega \in\left[0, \omega_{i}\right] \\ \frac{W^{*}}{\rho \gamma(\omega)} & \omega \in\left(\omega_{i}, \omega_{f}\right] \\ \frac{W}{\rho \gamma(\omega)} & \omega \in\left(\omega_{f}, \bar{\omega}\right]\end{cases}
$$

where $W$ and $W^{*}$ are the home and foreign wage rates, respectively. Note that Local firms and multinational (foreign) firms use local labor in their operation in our developing country while the remaining foreign firms (that produce their goods abroad) use foreign labor. At this point, it should also be clear to our reader that we rule out production fragmentation. We maintain in the rest of the paper that wages are normalized to unity both in our developing economy and abroad. Apart from the fact that our framework is partial equilibrium and therefore constant wages are inconsequential in our analysis, normalization of these wages has another important advantage: our focus in this paper is on FDI vs trade as well as liberalization FDI and trade at the presence of technology diffusion. Of course, we recognize that wage differential between developed and developing countries is a factor in a foreign firm decision to choose FDI rather than produce at its home country sell its product in the developing country. The channel that we focus in this paper is rather different. Even if there is no wage differential between a developed and developing country, a firm from a developing country may opt for FDI rather than export to a developing country if the combination of tariffs and FDI tax in the developing country permits.

Following eq. (6), it can be shown that profit for firm $\omega \in \Omega$ is given by:

$$
\pi(\omega)= \begin{cases}\frac{[\rho \gamma(\omega) P]^{\sigma-1}}{\sigma} E-\delta & \omega \in\left[\underline{\omega}, \omega_{i}\right] \\ \left(\tau+\frac{1}{\sigma}-1\right)[\rho \gamma(\omega) P]^{\sigma-1} E-\delta & \omega \in\left(\omega_{i}, \omega_{f}\right] \\ \left(\frac{[\rho \gamma(\omega) P]^{\sigma-1} E}{\sigma}-\delta-\delta_{f}\right) \nu & \omega \in\left(\omega_{f}, \bar{\omega}\right]\end{cases}
$$

where $\tau \geq 0$ and $v \geq 0$ identify the iceberg-type tariff rate and tax rate on multinational firms, respectively. ${ }^{10}$ That is, $(1-\tau)$ is the tariff rate and $(1-v)$ is the tax rate on profit of multinational corporations. Moreover, $\underline{\omega} \in \Omega$, where $0<\underline{\omega}<\omega_{i}$, is the local marginal good (firm) for which $\pi(\underline{\omega})=0$. This implies that all potential goods $\omega \in[0, \underline{\omega})$ will not be produced. ${ }^{11}$ Note also that in the context of our model, as in Melitz (2003), the more (less) technologically advanced a firm is in each of these intervals, the bigger (smaller) and more (less) profitable it will be. ${ }^{12}$

Proposition 1. Assume that $v>1-\sigma(1-\tau)$ and $\tau>\rho$. Then, for some $\delta_{f}>0$, there exists $\omega_{f} \in\left(\omega_{i}, \bar{\omega}\right)$ such that $\forall \omega \in\left(\omega_{i}, \omega_{f}\right]$ will be imported while $\forall \omega \in\left(\omega_{f}, \bar{\omega}\right]$ will be produced in the developing country by multinational firms through FDI.

Figure 1 shows the result of Proposition 1. For the right combination of taxes and the fixed cost of FDI, we will have an interior solution. If $v$ or $\tau$ is not sufficiently large, then all foreign firms would opt for exporting to our developing country or for FDI, resulting in a corner solution. Similarly, a restriction need to be imposed on $\delta_{f}$. If $\delta_{f}=0$, then all foreign firms may choose FDI even if $\tau>\rho$ and $\nu>1-\sigma(1-\tau)=1-(1-\tau) /(1-\rho)$. On the other hand, No foreign firm will opt for FDI if its fixed cost is too large. We will provide the a necessary range of FDI fixed costs in Proof of the proposition. Obviously, corner solutions are also possible where all foreign firms will choose either FDI or imports. However, such corner solutions are not interesting, given our objective in this paper. 


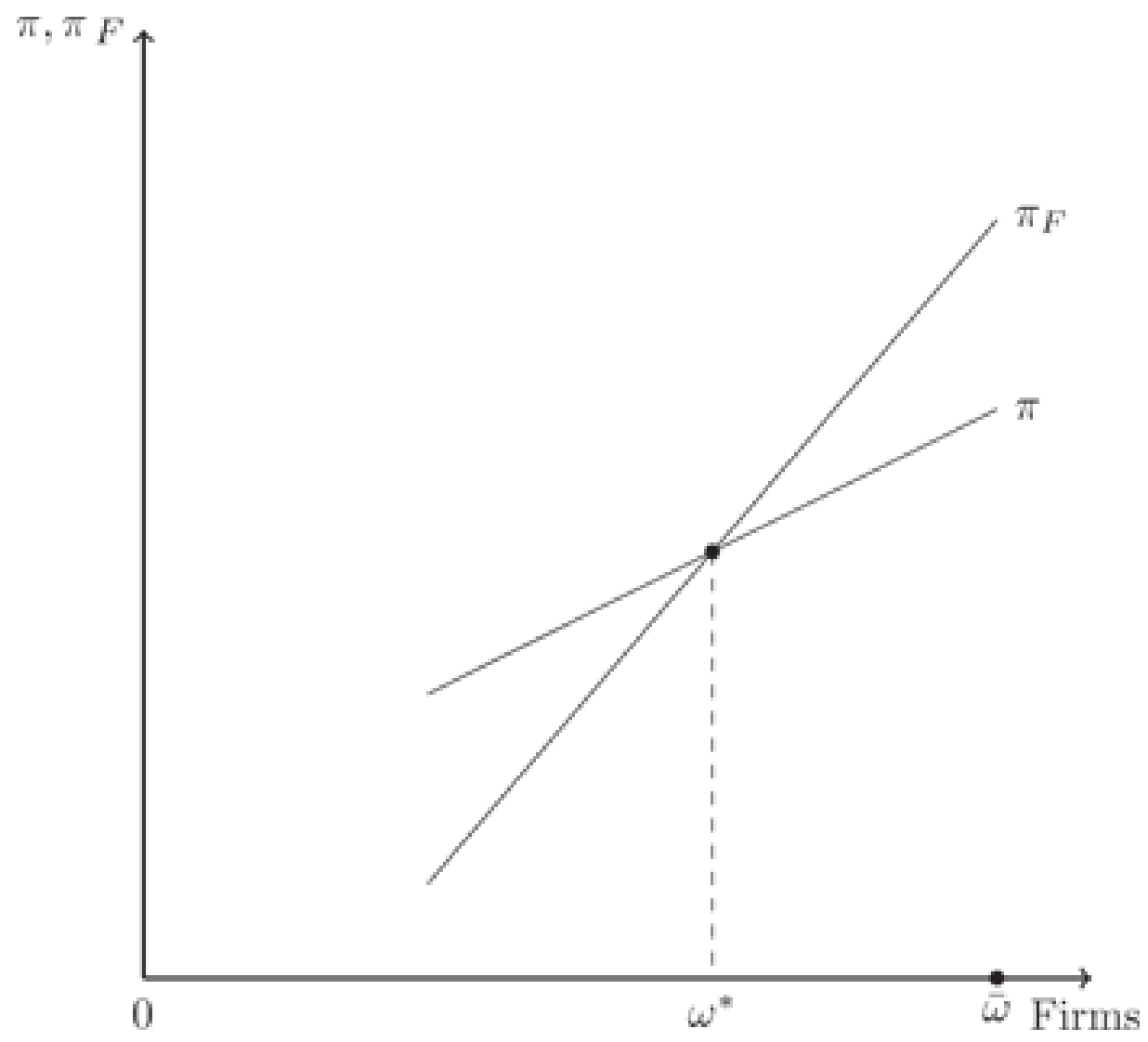

Figure 1: FDI vs. imports.

As discussed above, both tariff and tax rates are crucial in the decision by foreign firms on their choice of FDI vis-a-vis import. Given that the result of Proposition 1 holds, that is, the goods produced by the less technologically advanced foreign firms are imported by our developing economy while more technologically advanced foreign firms produce their goods through FDI in the developing country, it is interesting to derive the combination $v$ and $\tau$ that leaves the ranges of these kinds of foreign firms unchanged. Let $v=\phi(\tau)$ be such loci. The following proposition characterizes this relationship.

Proposition 2. $\phi(\tau)$ is nondecreasing. Moreover, $\phi(1)>1$ and there exists $\tilde{\tau} \in(0,1)$ for which $\phi(\tau)=0, \forall \tau \in$ $[0, \tilde{\tau}]$.

The above result formally highlights a relationship between profit tax rate on multinational corporations with FDI activities in the developing countries and the rate of tariffs. Since profit tax, tariffs and firm technological heterogeneity are the only factors that influence a firm's decision on FDI activities versus import, it only makes sense that a non-decreasing relationship must exist between the profit tax rate on multinationals and the tariff rates that keep the balance of FDI vis-a-vis imports unchanged. Consider a firm that produces the marginal good $\omega_{f}$. Now suppose the tax rate on multinationals falls, ceteris paribus. As a result, FDI becomes more attractive than producing the good abroad for the marginal firm, which motivates the firm to opt for FDI. Thus, such a change in tax rate increases FDI and reduces imports by our developing economy, moving the marginal firm/good to left on the spectrum. To keep the marginal firm unchanged, tariff rate must also fall. ${ }^{13}$ Figure 2 depicts $\phi$. 


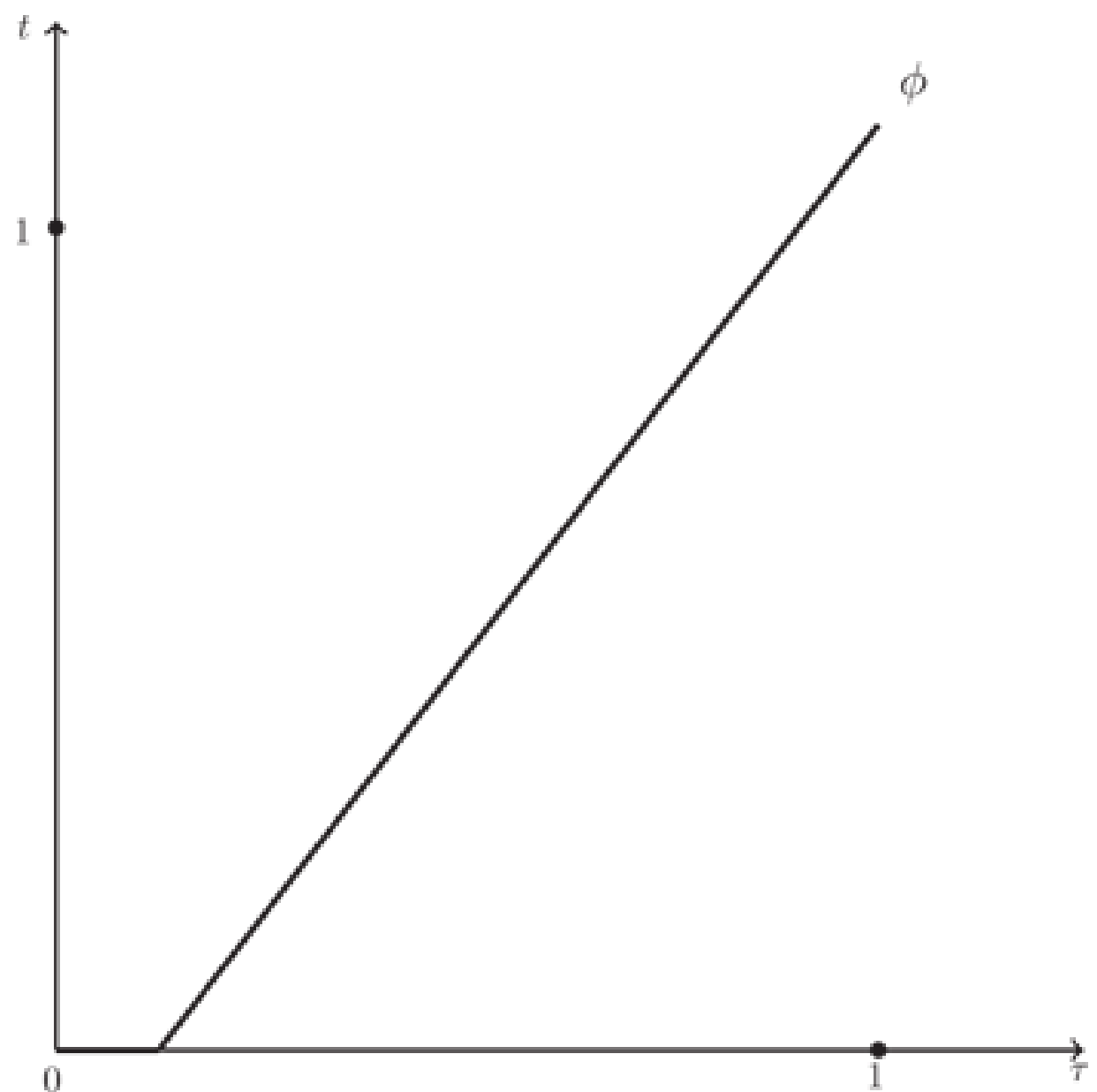

Figure 2: Relationship between tariff and FDI tax when $\sigma=2$.

\section{Technology Diffusion}

Multinational corporations and their transnational investments have been credited for the rapid diffusion of new technologies. In this section we turn to the issue of how FDIs by multinational corporations affect a developing economy. In formulating the channel through which technology diffuses, we take the view that the spread of technology depends on proportion of the firms within the industry that already have adapted the new technology. ${ }^{14}$ In our framework, we assume that multinational corporations use superior technologies, as formulated in the preceding section. Recall from the previous section that we assumed the local developing country firms are less technologically advanced than foreign firms and we showed that, among these more technological advanced foreign firms, the firms that engage in FDI activities are even more technologically advanced than those foreign firms that produce their goods abroad and export them to the developing country.

Hence, the spread of technology in the industry depends on the proportion of multinational corporations in the industry to all firms, denoted by $\mu \equiv\left(\bar{\omega}-\omega_{f}\right) /\left(\omega_{i}+\bar{\omega}-\omega_{f}\right) .{ }^{15}$ Clearly, $d \mu / d \omega_{f}<0$. We maintain all features of our model that we presented earlier in the paper, including the cost structure for multinationals, as before but we distinguish all foreign variables with an asterisk. However, our measure of technology for the local firms now also depends on $\mu$, that is, $\gamma(\omega, \mu), \forall \omega \in[0, \hat{\omega}]$, where $\gamma_{\omega}>0, \gamma_{\mu}>0, \gamma_{\mu \mu}<0$ and $\gamma_{\mu \omega}>0$. The second partial derivative states that the higher the proportion of multinational corporations in the developing country, the higher the level of technology of the local firms. However, the rate by which the presence of multinationals affects the local firm technologies is diminishing as postulated by the third partial derivative. ${ }^{16}$ The last partial derivative states that more technologically advanced local firms are more affected by the diffusion of technology than less technologically advanced local firms. Although this assumption is intuitive and realistic, the following simple example can illuminate the logic behind it. Consider the usage of computers by multinationals in their production process. A local firm must be using computers to be able to take advantage of diffusion of advancement in computer technology. ${ }^{17}$ To avoid repetition, we only restate parts of our model that has to be altered to reflect our formulation of technology diffusion. To do this, only 
the pricing rules and the profit functions for local firms will have to be modified. Accordingly, the pricing rule for local firms now is $p(\omega)=W /[\rho \gamma(\omega, \mu)], \forall \omega \in\left[0, \omega_{i}\right]$. Similarly, eq. (7) will have to be changed such that $\pi(\omega)=[\rho \gamma(\omega, \mu) P]^{\sigma-1} E / \sigma-\delta, \forall \omega \in\left[\underline{\omega}, \omega_{i}\right]$. For all other goods we need to simply replace $\gamma(\omega)$ with $\gamma^{*}(\omega)$, in eqs (6) and (7) for $\omega \in\left(\omega_{i}, \bar{\omega}\right]$.

It is straightforward to see that Propositions 1 and 2 hold under the presence of technological diffusion we introduced in this section. That is, it is plausible in our model that both FDI activities and imports take place and that the relationship between tariff rate and FDI tax rate is non-negative (in particular, such a relationship is strictly positive for all $v>0$ ), as seen in Figure $2 .{ }^{18}$ A direct corollary to these propositions is that the extent of FDI activities by multinational corporations depends on the combination of $v$ and $\tau$. Any change in this policy pair (whether due to a change in $\nu, \tau$ or both) will result in a change in marginal foreign firms $\omega_{f}$ causing a decrease or an increase in FDI activities. If tariff rate and (or) FDI tax change(s) such that $v>\phi(\tau)$, then $\omega_{f}$ decreases which means an increase in FDI activities and a decrease in the range of imported goods. Recall that tariff rate is $1-\tau$ and foreign investment tax rate is $1-\nu$. On the other hand, any change in policy mix that results in $v<\phi(\tau)$ will have the opposite effects.

A change in the balance of FDI versus imports have consequences for the developing economy. Apart from the standard arguments in the literature with regard to commercial policy changes, our economy will also be influenced via the effect trade and foreign investment policy mix has on FDI balance vs. imports and thus a change in $\mu$. Any change in $\mu$ will in turn affect the industry in question in our developing country. In the remaining of the paper let $\eta(\omega) \equiv \partial \gamma(\omega, \mu) / \partial \mu, \forall \omega \in\left[0, \omega_{i}\right]$. Based on formulation in the preceding section, the intra-industry relative prices are very essential. In particular, it is crucial to study the effect of a change in our policy mix on the intra-industry relative price of the local marginal firm, a result highlighted by the following proposition.

Proposition 3 If trade liberalization is not matched with FDI, it increases the aggregate industry price. Moreover, such trade liberalization lowers the intra-industry relative price of the home marginal firm if $\eta(\omega)$ is sufficiently smaller for less technologically advanced local firms than for more technologically advanced ones.

Intuitively, a reduction in trade barriers alone (i.e, without lowering barriers on FDI) will increase imports and reduce FDIs. As the level of FDI falls, technological diffusion will be restrained. This will have a negative impact on all local firms. However, the more technologically advanced firms will be affected more. The aggregate industry price rises. Since less technology diffusion results in a fall in productivity of all local firms which in turn leads to an increase in their prices. Thus, the aggregate industry price must rise. It is useful to highlight the channel through which the aggregate price will rise with trade liberalization of the sort we present here. In other words, trade liberalization without lowering taxes on FDI will encourage (discourage) import of foreign varieties (FDI), which lowers $\mu$. A lower $\mu$ will restrict the degree of technology diffusion, which in turn has a negative impact on all prices given our assumptions. Thus, we will experience an increase in aggregate industry price with this type of uni-dimensional liberalization. However, the price of a good produced by the least technologically advanced firm rises less. This results in a reduction of the intra-industry relative price of the good produced by the most technological backward firm. Recall that we use the intra-industry relative price as a measure of firm's intra-industry competitiveness. A lower relative price implies a stronger competitive position for a firm. Therefore, we conclude that such type of uni-dimensional liberalization leads to improvement of competitive position of less technological advanced local firms. Although this result is of interest in itself, it is also helpful in establishing a more interesting result that follows.

It is widely argued in policy circles that trade liberalization will in general (and especially in the developing countries) eliminate marginal firms (i.e., firms that barely can survive given the presence of some sort of protectionary trade policies). Examples of these marginal firms are infant, old and dying firms, and technologically backward firms. Some policy makers argue passionately against trade liberalization by appealing to these cases, while some advocate this view by offering economic analysis that supports such a position. Even the main stream trade theorists admit that such firms will disappear within the paradigm of standard trade theory, but they argue for trade liberalization from the stand view of overall welfare and efficiency. In this paper we offer a different point of view, formally stated by the following proposition.

Proposition 4 Unilateral trade liberalization alone (without foreign investment liberalization) leads to the protection of the least technologically advanced firms if $\eta(\omega)$ is sufficiently small for less technologically advanced local firms relative to that of more technologically advanced local firms.

According to the trade theory literature, trade liberalization has adverse effect on small and less productive local firms in importable sector. The above result presents a possibility that this may not be the case and that trade liberalization can indeed lead to the protection of technologically backward (and less productive) local firms. That is, this policy mix in a way shields the least technologically advanced local firm from foreign competition as it improves its competitive position within the industry. While this result may seem peculiar at the first 
sight, it is intuitive in the context of our theory and provides a deep insight. Since we have assumed firm technological heterogeneity in our model, the effect of liberalization differs across local firms. If trade liberalization is not coupled with liberalization FDI, the change in policy mix will encourage imports and discourage FDI. A reduction in FDI adversely impact transfer of technology from developed to the developing country. Since local firms are heterogeneous in their technology level, the adverse impact will differ across these local firms. On the other hand, it is also reasonable to assume that more technologically advance local firms are the main beneficiary of technology diffusion (i.e., $\eta(\omega)$ is larger for more high tech local firms). That is, technology diffusion has little effect on a technologically backward local firm. Now, less technology diffusion and its adverse effect on productivity raise the prices of home made varieties as well as industry aggregate price. However, the extent of increase is different across local firms. Backward firms experience a smaller raise in their prices compared with more technologically advanced firms. This will lead to a decrease in intra-industry relative price of more backward firms (see Proposition 3), implying an improvement in competitive position of these firms and an increase in their profits. ${ }^{19}$ To further clarify this fine point, we appeal to the example we stated in the introduction. Recall that the presence of multinational in footwear industry in India results in diffusion of technology in Indian footwear industry. Among shoe making firms in India, we have a technologically backward local shoemaker that produces hand made shoes on one end of spectrum of local firms, while on the other end of this spectrum we may have a fully automated shoe manufacturing firm. Now diffusion of computer technology in footwear industry in India has little or no impact on our hand-made shoe firm, while it has a significant impact on the other end of spectrum. Now if the policy mix discourages FDI and therefore restrains diffusion of technology in India, it would have little or no impact on producer of hand-made shoes, whereas it may have severe adverse effect on our fully automated shoe manufacturer, reducing intra-industry relative price for a hand-made shoe firm and increasing such a relative price for a high-tech shoe maker. Since profit of each local variety (and firm) is negatively related to its intra-industry relative price, the profit of a low-tech shoe making firm rises while it falls for a high-tech shoe maker.

This type of one-dimensional liberalization also affects the range of varieties that local firms produce. Recall that the marginal (low tech) firm that earns zero profit before the policy change will experience an increase. Its profit will be greater than zero as a result of this policy change and it will no longer be a marginal firm. This implies that the index of marginal good/firm falls. That is, new local variety/firms enter the market. Thus, we have the following corollary.

Corollary 5 Suppose that trade liberalization is not coupled with liberalization of FDI. Then, such type of trade liberalization will increase the number of local goods if $\eta(\omega)$ is sufficiently smaller for less technologically advanced local firms than for more technologically advanced firms.

\section{Welfare Analysis}

The impact of the interaction between trade liberalization and foreign investment policy, given the presence of technology diffusion channel of the type we considered here, on welfare is another interesting issue that we could address within the context of our model. ${ }^{20}$ First assume that a developing economy liberalizes trade in conjunction with foreign investment liberalization. More specifically, assume that these dual-liberalization policies take place along the curve $\phi$. Then it is straightforward to see that $d \mu=d P=0$. This leaves the welfare of our representative consumer unchanged, i.e., $d Q=D U=0$. Although this observation is interesting in itself, perhaps a more interesting scenario is to consider a change in policy mix that moves the FDI tax and tariff rate combination to above or below $\phi-$ loci, say trade liberalization alone.

To see the effect of a reduction in trade barriers (i.e., an increase $\tau$ ), we first highlight the effect of a change in $\mu$ on industry aggregate price. As we already established in Proof of Proposition 3 that $d P / d \mu<0$, a reduction in tariffs will lead to an increase in $\omega_{f}$ which implies a decrease in FDI activities. This, in turn, results in an increase in aggregate industry price. In other words, a rise in $\tau$, holding $v$ constant, will decrease FDI since some foreign firms will opt to export their goods rather than invest in the developing country. This leads to less diffusion of technology in South that ultimately lowers $\gamma$ for all local firms. All these will result in an increase in prices of all locally made goods as well as aggregate industry price. A rise in aggregate industry price will lower aggregate consumption and welfare, i.e., $d Q \equiv d U<0$. We highlight this result in the following proposition.

Proposition 6. Liberalizing trade without liberalization of FDI will lower welfare of the representative consumer in the developing economy.

Another related question that begs for an answer is to ask under what policy scenario welfare improvement can be guaranteed? We claim that welfare of the representative consumer in the developing country will unambiguity increase if trade liberalization is accompanied with sufficient foreign investment subsidies. At this point 
in the paper the rationale should be clear. Recall from Proposition 2 that $\phi(1)>1$, implying that to maintain no change in the balance of FDI when trade is fully liberalized, the foreign investment policy must be a subsidy. If the rate of subsidy is sufficiently large, then the balance of FDI increases. This will result in more technology diffusion in the developing country, which in turn lowers prices. A lower aggregate industry price will increase aggregate industry consumption and welfare of the representative consumer.

\section{Conclusion}

In this paper we have explored the interaction between trade liberalization and liberalization of FDI by a developing country and its effects on technology diffusion. One of the fundamental differences between developing and developed economies is that the developed countries are more technologically advanced. It has been observed that the activities of multinational corporations in developing countries would lead to spread of technology in these countries. We have formalized this observation in our analysis and studied how trade and FDI policies interact at the presence of technology diffusion.

We formulated a monopolistically competitive market in a developing country that is populated by a continuum of foreign (developed world) and local firms. We assumed that all these firms are technologically heterogeneous, all local firms are less technologically advanced than foreign firms, and that the operation of foreign firms in the developing economy leads to technology diffusion. We showed that there exists a policy mix of tariffs and foreign direct investment tax at which among the technologically superior foreign firms the more technologically advanced ones will engage in foreign direct investment in the developing country while others will opt to produce their goods abroad (their home country) and export them to the developing countries. This gives rise to endogenously determined (emerged) multinational corporations. More importantly, we showed that trade liberalization alone (i.e., without liberalization of foreign investment) by a developing country can lead to protection of the most technologically backward local firms. We also showed that such type of one dimensional liberalization is welfare reducing.

Both of these results have important policy implications for developing economies. First, the impacts of trade liberalization without liberalizing FDI on local firms depend on pattern of diffusion. We show that the less technologically advanced local firms (more often observed to be smaller firms) can be protected when a developing country lowers trade barriers if foreign direct investment is not liberalized. Given that firms in an industry are technologically heterogeneous and the pattern of technology diffusion is sufficiently biased toward more technologically advanced local firm, then trade liberalization without FDI liberalization can strengthen the competitive position of less advanced local firms within the industry and lead to their protection. Second, we also showed that trade liberalization without FDI liberalization by developing countries may paradoxically lower the welfare of the representative consumer when firms are technologically heterogeneous.

Our results open multiple avenues for empirical research as it is interesting to test some of the hypotheses and results introduced in this paper. For example, one can study the pattern of technology diffusion in developing countries and test whether it is in fact biased toward more advanced local firms. As another example, one can study whether the presence of multinational has significant effect on diffusion of technology in developing countries. A more elaborate empirical research may be able to isolate the effects of trade liberalization and liberalization of FDI, and their interaction, on an industry with firms that are technologically heterogeneous in a developing country. In addition to these potential econometric studies, an empiricist may use simulation and calibrate some of the crucial parameters of our model.

\section{Acknowledgments}

We would like to thank Eric Bond, Ron Jones and the participants of WEAI conference for their comments and suggestions. We are also grateful to two anonymous referees and the editor of this journal for their insightful comments that improved this version significantly. Reza Oladi acknowledges financial support from Utah Agricultural Experiment Station. The Usual caveat applies.

\section{Appendix A: Proofs}

Proof of Proposition 1 First note a necessary condition for import to take place is $\tau>(\sigma-1) / \sigma=\rho$, that is, any $\tau \leq \rho$ is prohibitive. Next, note that any good $\omega \in(\hat{\omega}, \bar{\omega}]$ will be produced in the developing economy through FDI if and only if 


$$
\left(\frac{[\rho \gamma(\omega) P]^{\sigma-1} E}{\sigma}-\delta-\delta_{F}\right) v>\left(\tau+\frac{1}{\sigma}-1\right)[\rho \gamma(\omega) P]^{\sigma-1} E-\delta
$$

Recall that $\tau+1 / \sigma-1=\tau-\rho$. Equation (8) implies that a foreign firm $\omega \in\left(\omega_{i}, \bar{\omega}\right)$ will opt for FDI versus export to our developing economy if and only if $(\nu-[1-\sigma(1-\tau)])[\rho \gamma(\omega) P]^{\sigma-1} E>\sigma\left[\nu \delta_{f}-(1-v) \delta\right]$. Clearly, the assumption of this proposition on $v$ and $\tau$ is essential. The above equation also implies that some foreign firms engage in FDI in the developing economy if $\delta_{f}<\left([v-[1-\sigma(1-\tau)]][\rho \gamma(\omega) P]^{\sigma-1} E / \sigma+(1-v) \delta\right) / \nu$.

Proof of Proposition 2 For the marginal firm $\omega_{f}$ to remain indifferent between FDI and import, we must have for all $\tau$ and $v$ :

$$
v=\frac{\left(\tau+\frac{1}{\sigma}-1\right)\left[\rho \gamma\left(\omega_{f}\right) P\right]^{\sigma-1} E-\delta}{\frac{\left[\rho \gamma\left(\omega_{f}\right) P\right]^{\sigma-1} E}{\sigma}-\delta-\delta_{f}}
$$

Differentiating eq. (9), we obtain $d v / d \tau=\sigma E\left[\rho P \gamma\left(\omega_{f}\right)\right]^{\sigma-1} /\left(E\left[\rho P \gamma\left(\omega_{f}\right)\right]^{\sigma-1}-\sigma\left(\delta+\delta_{f}\right)\right)>0$. Recall that $E\left[\rho P \gamma\left(\omega_{f}\right)\right]^{\sigma-1}-\sigma\left(\delta+\delta_{f}\right)>0$, otherwise no FDI activities would take place. In addition, by setting $v=0$ in eq. (9) we obtain $\tilde{\tau}=(\sigma-1) / \sigma+\delta /\left(E\left[\rho P \gamma\left(\omega_{f}\right)\right]^{\sigma-1}\right)>0$. Finally, again by using eq. (9), we get $\phi(1)=$ $\left(E\left[\rho P \gamma\left(\omega_{f}\right)\right]^{\sigma-1}-\sigma \delta\right) /\left(E\left[\rho P \gamma\left(\omega_{f}\right)\right]^{\sigma-1}-\sigma\left[\delta+\delta_{f}\right]\right)>1$. The inequality follows from the fact that $\delta_{F}>0$.

Proof of Proposition 3 First, re-write no-entry-exit (zero-profit) condition as:

$$
\pi(\underline{\omega})=\frac{1}{\sigma}[p(\underline{\omega})]^{1-\sigma} P^{\sigma} Q-\delta=0
$$

Differentiating eqs (2), (10) as well as the definition of $\tilde{\xi}(\underline{\omega})$ with respect to $\mu$, we obtain:

$$
\begin{gathered}
\frac{d P}{d \mu}-\frac{\Phi}{\sigma-1}[p(\underline{\omega})]^{1-\sigma} \frac{d \underline{\omega}}{d \mu}=\Lambda \\
\xi(\underline{\omega}) \frac{d P}{d \mu}+\frac{\partial \pi(\underline{\omega}, .)}{d \omega} \frac{d}{d \mu}=-\frac{1}{\rho[\gamma(\underline{\omega}, .)]^{2}} \eta(\underline{\omega})
\end{gathered}
$$

$\frac{p(\underline{\omega})}{P^{2}} \frac{d P}{d \mu}+\frac{d \xi(\underline{\omega}, .)}{d \mu}=-\xi(\underline{\omega}) \frac{1}{\gamma(\underline{\omega})} \eta(\underline{\omega})$ where $\Phi \equiv\left[\int_{\underline{\omega}}^{\bar{\omega}} p(\omega) d \omega\right]^{\frac{\sigma}{1-\sigma}}>0$ and $\Lambda \equiv$ $-\rho \Phi \int_{\underline{\omega}}^{\bar{\omega}}[1 / \rho \gamma(\omega, .)]^{2-\sigma} \eta(\omega) d \omega<0$. Solving the system of eqs (11)-(5), we obtain that:

$$
\begin{gathered}
\frac{d P}{d \mu}=-\frac{\rho \Phi}{\Psi}\left(\frac{d \pi(\underline{\omega}, .)}{d \omega} \int_{\underline{\omega}}^{\bar{\omega}}[p(\omega)]^{2-\sigma} \eta(\omega) d \omega+[p(\underline{\omega})]^{1-\sigma} \eta(\underline{\omega})\right) \\
\frac{d \underline{\omega}}{d \mu}=-\frac{1}{\Psi}\left(\frac{1}{\rho[\gamma(\underline{\omega})]^{2}} \eta(\underline{\omega})-\rho \Phi \xi(\underline{\omega}) \int_{\underline{\omega}}^{\bar{\omega}}[p(\omega)]^{2-\sigma} \eta(\omega) d \omega\right) \xi(\underline{\omega}) \frac{d \pi(\underline{\omega})}{d \omega} \\
\frac{d \xi(\underline{\omega})}{d \mu}=-\frac{1}{\Psi}\left(\frac{1}{\gamma(\underline{\omega})} \eta(\underline{\omega})-\frac{\rho \Phi}{p} \int_{\underline{\omega}}^{\bar{\omega}}[p(\omega)]^{2-\sigma} \eta(\omega) d \omega\right) \xi(\underline{\omega}) \frac{d \pi(\underline{\omega})}{d \omega}
\end{gathered}
$$

where $\Psi \equiv[d \pi(\underline{\omega}) / d \omega][\Phi /(\sigma-1)][p(\underline{\omega})]^{1-\sigma} \xi(\underline{\omega})>0$. It follows from eq. (13) that $d P / d \mu<0$. Since we assumed $\gamma_{\mu \omega}>0$, it implies that $\eta(\omega)>\eta(\underline{\omega}), \forall \omega \in(\underline{\omega}, \hat{\omega}]$. We then conclude from eq. (15) that $d \xi(\underline{\omega}) / d \mu>0$ if the condition of the proposition is met. ${ }^{21}$ Finally, since an increase $\tau$ which is not matched with an increase in $t$ will result in $t<\phi(\tau)$, such a type of trade liberalization will lead to an increase in $\omega^{*}$, i.e. a reduction in FDI. This in turn lowers $\mu$ as $d \mu / d \omega^{*}<0$. Therefore, the aggregate industry price rises while the intra-industry price of local marginal good falls as a result of such a form of trade liberalization. 
Proof of Proposition 4 It follows from eq. (7) that profit for the marginal local firm is given by:

$$
\pi(\underline{\omega})=\frac{[\rho \gamma(\underline{\omega}) P]^{\sigma-1}}{\sigma} E-\delta
$$

Differentiate eq. (16) with respect to $\mu$ and simplify to obtain:

$$
\frac{d \pi(\underline{\omega})}{d \mu}=\frac{p(\underline{\omega})[\xi(\underline{\omega})]^{-\sigma} Q}{\sigma}\left(\frac{\epsilon}{P} \frac{d P}{d \mu}-\frac{\frac{\partial \gamma}{\partial \mu}}{\rho \gamma^{2} p(\underline{\omega})}-\frac{\sigma}{\xi(\underline{\omega})} \frac{d \xi(\underline{\omega})}{d \mu}\right)
$$

Next, using our earlier assumption of unit elasticity of industry aggregate demand, zero-profit condition of our (initial) marginal firm, as well as differentiating the definition of intra-industry price of the local marginal firm, we simplify eq. (17) to:

$$
\frac{d \pi(\underline{\omega})}{d \mu}=\frac{\delta(1-\sigma)}{\xi(\underline{\omega})} \frac{d \xi(\underline{\omega})}{d \mu}
$$

Recall from zero-profit condition of home marginal firm we can obtain $p(\underline{\omega})[\xi(\underline{\omega})]^{-\sigma} Q / \sigma=\delta$. As we have already established by Proposition 3 that $d \xi(\underline{\omega}) / d \mu>0$ if the condition of the proposition is met, we conclude from eq. (18) that $d \pi(\underline{\omega}) d \mu<0$ if the conditions of our proposition is met since $\sigma>1$. Finally, since trade liberalization alone (without a change in foreign investment tax policy) implies an increase in $\tau$ without a change in $v$, such a policy mix change will lead to $v<\phi(\tau)$, which in turn results in an increase in $\omega_{f}$, i.e., a reduction in FDI. This reduction in FDI lowers $\mu$. Therefore, such a change in policy mix leads to an increase in profit of the most technologically backward firm $\underline{\omega}$.

Proof of Corollary 1 Recall eq. (14) in Proof of Proposition 3. It implies that the bracketed term will be negative if $\eta(\omega)$ is sufficiently small for the marginal local firms, which in turn implies that $d \underline{\omega} / d \mu>0$. Now, since such trade liberalization lowers $\mu$, we conclude that $\underline{\omega}$ falls, i.e., more low tech local firms will enter the market and more local goods will be produced.

Proof of Proposition 5 Directly follows from $d Q \equiv d U<0$.

\section{Appendix B: An Alternative Complex Model}

In this appendix we will show that the assumption of not having a zero-profit (marginal) foreign firm has little consequence on our results and that our core argument remains valid if we relax this assumption. Let the set of local goods be $\Omega$ and the set of foreign goods be denoted by $\Omega^{*}$. Let $\Omega=\left[0, \omega_{i}\right]$ and $\Omega^{*}=[\hat{\hat{\omega}}, \overline{\bar{\omega}}]$. We index all goods such that $\omega_{i}<\hat{\hat{\omega}}$. We further assume that $\partial \gamma(\omega ; \mu) / \partial \omega>0, \forall \omega \in \Omega, \partial \gamma^{*}(\omega) / \partial \omega<0, \forall \omega \in \Omega^{*}$ and $\gamma\left(\omega_{i}\right)<\gamma^{*}(\hat{\hat{\omega}})$. This last assumption implies that any foreign firm is more technologically advanced than all local firms. Figure 3 depicts $\gamma$ and $\gamma^{*}$. We also redefine $\mu \equiv\left(\omega_{f}-\hat{\hat{\omega}}\right) /\left(\hat{\omega}+\omega_{f}-\hat{\hat{\omega}}\right)$. It easily can be seen that $d \mu / d \omega_{f}>0$. The aggregate output is now defined as $Q \equiv U=\left[\int_{\omega \in \Omega \cup \Omega^{*}}[q(\omega)]^{\rho} d \omega\right]^{\frac{1}{\rho}}$ and its associated aggregate price is given by $P=\left[\int_{\omega \in \Omega \cup \Omega^{*}}[p(\omega)]^{1-\sigma} d \omega\right]^{\frac{1}{1-\sigma}}$. Equations (3)-(5), (6) and (7) hold as in Section 2, albeit eqs (6) and (7) are modified as in Section 3. Finally, we have to add a similar zero-profit (no-entry-exit condition) for foreign firms. We define the foreign marginal firm $\bar{\omega} \in \Omega^{*}$ such that $\pi(\bar{\omega})=0$. We now revisit our earlier results. It is straightforward to see that Propositions (1) and (2) are not influenced by the range of possible foreign goods/firms. However, as changes in tariff rate affect the range of foreign goods, we have to revisit Propositions (3)-(5). Note that in our current formulation $\bar{\omega}$ is the foreign marginal firm. A reduction in the tariff rate will push this boundary outward, increasing the range of foreign goods/firms. That is, the zero-profit firm index increases. It is this possibility that may question the validity of some of the results we obtained in preceding sections. However, we will show in the rest of this appendix that this is not the case and that this more complex formulation has little impact on our earlier results. We start with the effect of a reduction in tariff rate on aggregate industry price in the following proposition. 


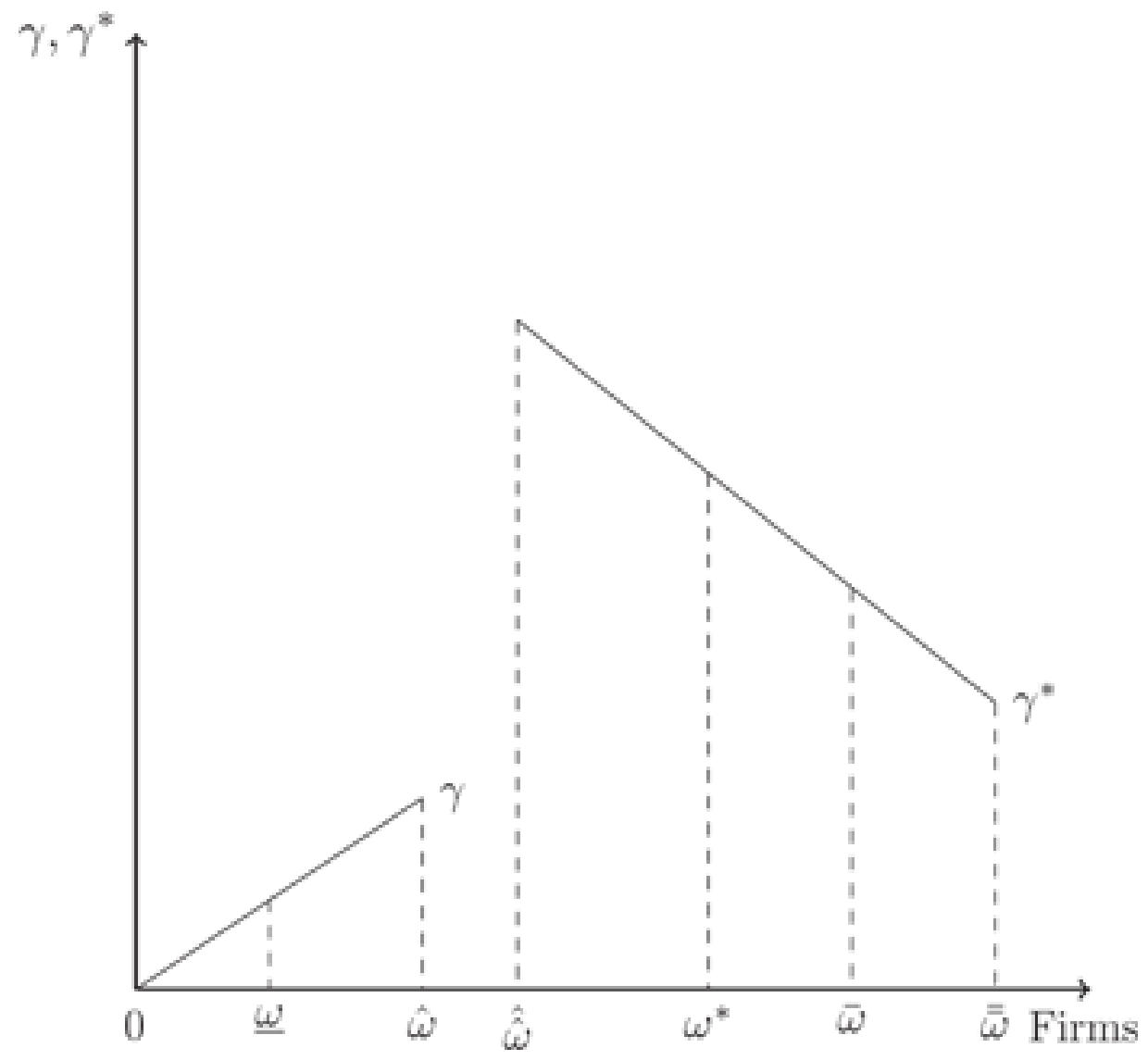

Figure 3: Technology levels for foreign and local firms.

Proposition 7 A decrease in tariff rate without a change in the tax rate on multinational corporations will increase the aggregate industry price.

Proof The aggregate price can be written as:

$$
P=\left[\int_{\underline{\omega}}^{\hat{\omega}}[p(\omega)]^{1-\sigma} d \omega+\int_{\hat{\omega}}^{\bar{\omega}}[p(\omega)]^{1-\sigma} d \omega\right]^{\frac{1}{1-\sigma}}
$$

By differentiating eq. (19), home and foreign zero-profit conditions for marginal firms, as well as the definition of intra-industry price for the home marginal firm, we obtain:

$$
\begin{gathered}
\frac{d P}{d \mu}-\frac{\Delta[p(\underline{\omega})]^{1-\sigma}}{\sigma-1} \frac{d \underline{\omega}}{d \mu}+\frac{\Delta[p(\bar{\omega})]^{1-\sigma}}{\sigma-1} \frac{d \bar{\omega}}{d \mu}=\Lambda \\
\xi(\underline{\omega}) \frac{d P}{d \mu}+\left(\frac{1}{\sigma-1}\right) \frac{d \pi(\underline{\omega})}{d \omega} \frac{d \underline{\omega}}{d \mu}=-\frac{\eta(\underline{\omega})}{\rho[\gamma(\underline{\omega})]^{2}} \\
\xi(\bar{\omega})(\sigma-1) \frac{d P}{d \mu}+\frac{d \pi(\bar{\omega})}{d \omega} \frac{d \bar{\omega}}{d \mu}=-\frac{p(\bar{\omega})}{\alpha\left(\tau+\frac{1}{\sigma}-1\right)} \\
\frac{p(\underline{\omega})}{P^{2}} \frac{d P}{d \mu}+\frac{d \xi(\underline{\omega})}{d \mu}=-\xi(\underline{\omega}) \frac{\eta(\underline{\omega})}{\gamma(\underline{\omega}, .)]}
\end{gathered}
$$

where $\Delta \equiv P^{\sigma}>0, \Lambda \equiv-\rho \Delta \int_{\underline{\omega}}^{\hat{\omega}}[1 / \rho \gamma(\omega, .)]^{2-\sigma} \eta(\omega) d \omega<0, \alpha \equiv d \mu / d \tau<0$, and $\eta(\omega)$ is as defined in Section 3. Solve the system of eqs (20) $-(23)$ to obtain:

$$
\frac{d P}{d \mu}=\frac{1}{(\sigma-1) \Gamma}\left(\Lambda \frac{d \pi(\underline{\omega})}{d \omega} \frac{d \pi(\bar{\omega})}{d \omega}-\frac{\Delta[p(\underline{\omega})]^{1-\sigma} \xi(\underline{\omega})}{\rho[\gamma(\underline{\omega})]^{2}} \frac{d \pi(\bar{\omega})}{d \omega}-\frac{\Delta[p(\underline{\omega})]^{-\sigma}}{\alpha(\sigma-1)\left(\tau+\frac{1}{\sigma}-1\right)} \frac{d \pi(\underline{\omega})}{d \omega}\right)
$$


where $\Gamma \equiv \frac{1}{\sigma-1}\left(\frac{d \pi(\underline{\omega})}{d \omega} \frac{d \pi(\bar{\omega})}{d \omega}+\Delta \xi(\underline{\omega})[p(\underline{\omega})]^{1-\sigma} \frac{d \pi(\bar{\omega})}{d \omega}-\Delta \xi(\bar{\omega})[p(\bar{\omega})]^{1-\sigma} \frac{d \pi(\underline{\omega})}{d \mu}\right)$. Since $\Delta>0, \frac{d \pi(\underline{\omega})}{d \omega}>0$, and $\frac{d \pi(\bar{\omega})}{d \omega}<0$, we conclude that $\Gamma<0$. In turn, this implies that $\frac{d p}{d \mu}<0$. Recall also that $\Lambda<0$ and $\alpha<0$.

As we observed throughout the paper, the relative intra-industry price for each firm is a determining factor for its viability since it defines the firm's intra-industry competitive position. Our main result regarding the fate of technologically backward local firms in a developing country when faced with trade liberalization (without liberalizing FDI) also hinges on such firms' intra-industry relative prices. Therefore, it is important to revisit the effect of liberalization on intra-industry relative price within our more general model. The following proposition addresses this robustness.

Proposition 8 Suppose trade liberalization is not matched with FDI liberalization in a developing country. Then, such type of trade liberalization will lower the intra-industry relative price of the home marginal firm if $\eta(\omega)$ is sufficiently small for this firm and it is larger for the more technologically advanced local firms than for the less technologically advanced one (i.e., $\eta$ is increasing in index of local firms $\omega$ ).

Proof By solving the system of eqs (20)-(23) for $d(\underline{\xi}) / d \mu$, we obtain:

$$
\frac{d \xi(\underline{\omega})}{d \mu}=\frac{-\xi(\underline{\omega})}{\Gamma(\sigma-1)}\left(\frac{\Lambda}{p} \frac{d \pi(\underline{\omega})}{d \omega}+\frac{\Delta \xi(\underline{\omega})[p(\bar{\omega})]^{1-\sigma}}{\alpha(\sigma-1)\left(\tau+\frac{1}{\sigma}-1\right)}+\frac{\eta \underline{(\underline{\omega})}}{\gamma(\underline{\omega})}\left[\frac{d \pi(\underline{\omega})}{d \omega}-\Delta \xi(\underline{\omega})[p(\underline{\omega})]^{1-\sigma}\right]\right) \frac{d \pi(\bar{\omega})}{d \omega}
$$

Recall from Proof of Proposition 6 that $\Gamma<0$. Recall also that $\Delta>0, d \pi(\underline{\omega}) / d \omega>0, d \pi(\bar{\omega}) / d \mu<0$, and $\alpha<0$. Therefore, the first term, second term, and the forth term in parenthesis are all negative while the third term is positive. However, if the condition of proposition is met (i.e., $\eta(\underline{\omega})$ is sufficiently small and $\eta(\omega))$ is increasing in $\omega$, the entire expression in parenthesis will be negative. Thus, we conclude that $d \xi(\underline{\omega}) / d \mu>0$ if the condition on the pattern of diffusion is met.

Since intra-industry relative price of the most technologically backward firm falls if $\mu$ falls as a result of trade liberalization, it is possible that trade liberalization with no foreign investment liberalization, results in protection of a backward local firm.

Finally, it is interesting to see whether the result of Proposition 5 is robust. Proposition 6 shows that the industry aggregate price rises as a result of trade liberalization without liberalizing foreign investment. As stated earlier in the paper, the driving force behind this unconventional result is the effect that ensuing change in FDI balance has on diffusion of technology to the local firms. Therefore, an increase in industry aggregate price will result in loss in welfare of the representative consumer, as stated in Proposition 5.

\section{Notes}

${ }^{1}$ See also Anwar (2009) and Chakrabarti (2001), 2003)), Chao and Yu (2000) .

${ }^{2}$ See also Mukherjee (2006) and Jones and Marjit (2001), among others.

${ }^{3}$ As we will address shortly, among these papers, Helpman, Melitz, and Yeaple (2004) and Baldwin and Forslid (2010) are more closely related to our paper.

${ }^{4}$ See Oladi, Beladi, and Chau (2008) for spillover effects of MNCs on export quality of developing countries.

${ }^{5}$ As examples of unidimensional liberalization, see Jones (1967) and Oladi (2005) for identical good models and Melitz (2003) for heterogenous firms.

${ }^{6}$ Our research is also related to growth and international trade literature vis-a-vis trade liberalization, FDI, and imitation. See Baldwin and Forslid (2000) and Grieben and Sener (2009) for trade liberalization and growth and Branstetter and Saggi (2011) and Glass and Saggi (2002) for FDI.

${ }^{7}$ As we will see shortly every firm is identified with one good as shown by Dixit and Stiglitz (1977).

${ }^{8}$ For simplicity we assume that FDI is north-south although several successful multinational firms such as Tata and Infosys from India in recent years (even in technologically intensive sectors) originate in developing/emerging countries. Moreover, for sake of tractability, we assume that firms on average are more productive in developed countries than in developing countries.

${ }^{9}$ That is, we need not to make this assumption here. We merely do this for the sake of presenting eq. (5).

${ }^{10}$ Profit function for any importing foreign firm $\omega \in\left(\omega_{i}, \omega_{f}\right]$ is defined as $\pi(\omega)=p(\omega) q(\omega) \tau-\delta-q(\omega) / \gamma(\omega)$. By using eqs (3)-(6), we obtain the second line of eq. (7).

${ }^{11}$ Note that as in Dixit and Stiglitz (1977), these zero-profit conditions will be sufficient to pin down the range of firms in each category and close our equilibrium.

${ }^{12}$ One may suggest that there may also be some foreign firms that are not active under current market conditions. That is, some range of low tech foreign firms would have negative profit and therefore they are inactive (i.e., $\omega_{i}$ is endogenous). Although the model we present in this section does not allow for such possibility, we consider a more complex model whereby some foreign firms are inactive as they would have negative profit in Appendix B. We show in this appendix that our results are robust regarding the simplifying assumption of the current section. For this reason, we prefer to present our results using our simpler model. 


\begin{abstract}
${ }^{13}$ Although we did not consider the wage differential motivation of FDI by assuming equal wages in developed and developing countries in order to isolate our bi-dimensional policy channel, one can easily see that such sort of relationship exists when there is wage differential between developing and developing economies, assuming that again wage differential remain the same. It is also noteworthy that although we make a distinction between the effects of $v$ and $\tau$ on FDI, it is possible that tariff cuts may also stimulate FDI. For example, this could occur if production is fragmented. However, we rule out this possibility.

${ }^{14}$ See Mansfield (1961) which introduced this diffusion channel by imitating the spread of an epidemic disease. Obviously, there are other channels through which technology may be transfered from developed to developing economies, such as imports of intermediate goods. However, the focus of our paper is on the effect international corporations may have in technology diffusion.

${ }^{15}$ Operation of multinational corporation is one channel through which technology may diffuse in a developing country. By focusing on this channel in this paper by no means suggests that it is the only channel. In fact, technology may also diffuse in this country through imports of technological intensive goods. Also, as an alternative to our formulation whereby proportion of multinational to all firms in a developing country is a determining factor in technology diffusion, one can use the proportion of output produced by the multinationals. In addition, Although we maintain that the range of foreign firms are fixed and therefore all foreign firms are active and have strictly positive profits, this assumption is inconsequential as far as our results re concerned. As we will explain shortly, we will relax this assumption in Appendix B and show that our main results are robust.

${ }^{16}$ The symmetric nature of the dependence of state of technology on proportion of multinationals in the developing countries implies that technology depreciates. That is, the fact that a reduction in $\mu$ lowers the state of technology used by local firms stems from its depreciation. There is a strong body of literature that postulates this idea .

${ }^{17}$ A more micro-foundation approach in formulating the effects of technology diffusion may be considered as an alternative to our set-up. Perhaps, such alternative set-ups would be more appropriate if one is interested in details of technology adoption by firms. However, our objective is to study the effects of technology diffusion (assuming that it would be adopted) on firms and the industry as well as the effects of liberalization policies through the new channel of technology diffusion rather than the the adoption process that may be a subject of future research.

${ }^{18}$ Although there are other conceivable equilibria at which either imports or FDI activities take place, these cases are not interesting in our context. Therefore, as stated in the preceding section, we focus on an equilibrium scenario under which some foreign firms opt for FDI activities while others decide to produce their goods abroad and import them to the developing country.

${ }^{19}$ The most crucial feature of our model that gives rise to this result is the pattern of technology diffusion in the developing country. If we assume that the most backward firms benefit significantly more from technology diffusion, then the converse of our result may occur, i.e., this sort of policy change will lower the intra-industry relative price of low tech firms and their competitive position in the industry. To see this point, suppose an extreme form of technology diffusion whereby the most backward firms in our developing economy are the beneficiary of diffusion and that more technologically advanced firms are self sufficient and thus will not benefit from technology diffusion. Specifically, let $\eta(\bar{\omega})$ be very large. Then, the sort of trade liberalization we address here would reduce diffusion of technology to marginal firm, lowering its productivity and raising its intra-industry relative price. In turn, this will the force marginal firm to exit the industry. That is, the most backward small firm will be a loser of trade liberalization under this scenario.

${ }^{20}$ Note that the notion of welfare that we discuss here is in its partial equilibrium sense.

${ }^{21}$ To see this more clearly, let $\eta(\underline{\omega})=0$. Then, it follows directly from eq. (15) that $d \xi(\underline{\omega}) / d \mu>0$.
\end{abstract}

\title{
References
}

Anwar, S. 2009. “Sector Specific Foreign Investment, Labour Inflow, Economies of Scale and Welfare.” Economic Modelling 26: 626-630.

Baldwin, R. E., and R. Forslid. 2000. "Trade Liberalisation and Endogenous Growth: A Q-theory Approach." Journal of International Economics 50: 497-517.

Baldwin, R. E., and R. Forslid. 2010. “Trade Liberalization with Heterogeneous Firms.” Review of Development Economics 14: 161-176.

Batra, R., and R. Ramachandran. 1980. "Multinational Firms and the Theory of International Trade and Investment." American Economic Review 70: 278-290.

Beladi, H., and R. Oladi. 2011. "An Elementary Proposition on Technical Progress and Non-traded Coods." Journal of Mathematical Economics 47: 68-71.

Beladi, H., and R. Oladi. 2016. “On Mergers and Agglomeration.” Review of Development Economics 20: 345-358.

Branstetter, L., and K. Saggi. 2011. “Intellectual Property Rights, Foreign Direct Investment and Industrial Development.” Economic Journal 121: 1161-1191.

Chakrabarti, A. 2003. "A Theory of the Spatial Distribution of Foreign Direct Investment." International Review of Economics and Finance 12: 149-169.

Chakrabarti, A. 2001. “The Determinants of Foreign Direct Investments: Sensitivity Analyses of Cross-Country Regressions." Kyklos 54: 89-114.

Chao, C. -C., and E. S. H. Yu. Domestic Equity Controls of Multinational Enterprises. The Manchester School 2000:321-330. 68.

Chao, C. -C., and E.S.H. Yu. Foreign-Investment Tax and Tariff Policies in Developing Countries. Review of International Economics 1997:47-62. 5.

Dinopoulos, E., and B. Unel. 2013. “A Simple Model of Quality Heterogeneity and International Trade." Journal of Economic Dynamics and Control 37: 68-83.

Dixit, A. K., and J. E. Stiglitz. 1977. “Monopolistic Competition and Optimum Product Diversity." American Economic Review 67: 297-308.

Findlay, R. 1978. “Relative Backwardness, Direct Foreign Investment, and the Transfer of Technology: A Simple Dynamic Model." Quarterly Journal of Economics 92: 1-16.

Business, Fox Could Free-trade Mean Bad News for Small Business? 2013, http://www.foxbusiness.com/features/2013/07/10/could-free-trademean-bad-news-for-small-business.html.

Class, A. J., and K. Saggi. 2002. "Intellectual Property Rights and Foreign Direct Investment." Journal of International Economics 56: 387-410.

Crieben, W. -H., and F. Sener. Clobalization, Rent Protection Institutions, and Coing Alone in Freeing Trade. European Economic Review 2009:1042-1065. 53.

Helpman, E., M. J. Melitz, and S. R. Yeaple. 2004. “Export versus FDI with Heterogeneous Firms.” American Economic Review 94: 300-316. 
Jones, R. W. 1967. “International Capital Movements and the Theory of Tariffs and Trade.” The Quarterly Journal of Economics 81: 1-38. Jones, R. W., and S. Marjit. 2001. "The Role of International Fragmentation in the Development Process." American Economic Review 91: 363-366.

Krishna, P., and D. Mitra. 1998. “Trade Liberalization, Market Discipline and Productivity Growth: New Evidence from India." Journal of Development Economics 56: 447-462.

Krugman, P. 1980. “Scale Economies, Product Differentiation, and the Pattern of Trade." American Economic Review 70: 950-959.

Mansfield, E. 1961. "Technical Change and the Rate of Imitation." Econometrica 29: 741-766.

Marjit, S. 1991. "Incentives for Cooperative and Non-cooperative R and D in Duopoly." Economics Letters 37: 187-191.

Marjit, S., and S. Kar. 2012. "Firm Heterogeneity, Informal Wage and Cood Governance." Review of Development Economics 16: 527-539.

Melitz, M. J. 2003. "The Impact of Trade on Intra? Industry Reallocations and Aggregate Industry Productivity." Econometrica 71: 1695-1725.

Mukherjee, A. 2011. "Competition, Innovation and Welfare." Manchester School 79: 1045-1057.

Mukherjee, A. 2010. “A Note on Firm-Productivity and Foreign Direct Investment." Economics Bulletin 30: 2107-2111.

Mukherjee, A. 2006. "Patents and R\&D with Imitation and Licensing." Economics Letters 93: 196-201.

Oladi, R. 2005. “Stable Tariffs and Retaliations." Review of International Economics 13: 205-215.

Oladi, R., H. Beladi, and N. Chau. 2008. "Multinational Corporations and Export Quality." Journal of Economic Behavior \& Organization 65: 147-155.

$\mathrm{Pi}$, J., and Y. Zhou. 2014. "Foreign Capital, Public Infrastructure, and Wage Inequality in Developing Countries." International Review of Economics \& Finance 29: 195-207.

Ruffin, R. J. 1979. “Border Tax Adjustments and Countervailing Duties.” Weltwirtschaftliches Archiv 115: 351-355. 